CLINICAL STUDY

\title{
Prevalence of IGF1 deficiency in prepubertal children with isolated short stature
}

\author{
T Edouard $^{1,4}$, S Grünenwald ${ }^{2}$, I Gennero ${ }^{3,4}$, J P Salles ${ }^{1,4}$ and M Tauber ${ }^{1,4}$ \\ ${ }^{1}$ Department of Paediatric Endocrinology, Hôpital des Enfants, Toulouse, France, ${ }^{2}$ Department of Endocrinology, Hôpital Larrey, Toulouse, France, \\ ${ }^{3}$ Department of Biology and ${ }^{4}$ INSERM U563, Department of Lipoprotéines et Médiateurs Lipidiques, Hôpital Purpan, Toulouse, France \\ (Correspondence should be addressed to M Tauber; Email: taubermt@chu-toulouse.fr)
}

\begin{abstract}
Background/aims: 'Primary IGF1 deficiency (IGFD)' is defined by low levels of IGF1 without a concomitant impairment in GH secretion in the absence of secondary cause. The aims of this study were to evaluate the prevalence of non-GH deficient IGFD in prepubertal children with isolated short stature (SS) and to describe this population.

Methods: This retrospective study included all children with isolated SS seen in our Pediatric Endocrinology Unit from January 2005 to December 2007. Children were included based on the following criteria: i) SS with current height SDS $\leq-2.5$, ii) age $\geq 2$ years, and iii) prepubertal status. Exclusion criteria were: i) identified cause of SS and ii) current or past therapy with rhGH. IGF1-deficient children were defined as children without GH deficiency and with IGF1 levels below or equal to -2 SDS.

Results: Among 65 children with isolated SS, 13 (20\%) had low IGF1 levels, consistent with a diagnosis of primary IGFD, four of which were born small for gestational age and nine were born appropriate for gestational age. When compared with non-IGFD children, IGFD children had higher birth weight $(-0.7$ vs -1 SDS, $P=0.02)$ and birth height $(-1.7$ vs -2 SDS, $P=0.04)$ and more delayed bone age (2.6 vs 1.7 years, $P=0.03$ ).

Conclusion: The prevalence of primary IGFD was $20 \%$ in children with isolated SS. Concerning the pathophysiology, our study emphasizes that IGFD in some children may be secondary to nutritional deficiency or to maturational delay.
\end{abstract}

European Journal of Endocrinology $16143-50$

\section{Introduction}

The GH-insulin-like growth factor 1 (IGF1) system could be viewed like other endocrine systems, with a central tropic hormone, GH, and a peripherally active hormone, IGF1.

Clinical trials have demonstrated the long-term efficacy of recombinant human (rh) GH treatment in children with GH deficiency (GHD) and also nonGH-deficient short stature (SS; Turner syndrome, idiopathic SS (ISS), small for gestational age (SGA), Prader-Willi syndrome) (1-5).

Since the late 1990's, the concept of 'IGF1 deficiency' (IGFD) has been defined including the dual (i.e. direct and indirect) effect of GH. Thus, any impairment in IGF1 levels resulting from diminished $\mathrm{GH}$ secretion could be termed 'secondary IGFD', and a decrease in IGF1 production without a concomitant impairment in $\mathrm{GH}$ secretion could be termed 'primary IGFD' (6). These children were selected for clinical trials with rhIGF-I: they had severe SS, normal or high-GH levels and the only impediment to normal growth was their inability to produce IGF1 in response to $\mathrm{GH}$.

The first children treated with rhIGF-I were those with SS resulting from defects in $\mathrm{GH}$ action due to $\mathrm{GH}$-receptor (GHR) abnormalities or GH inactivating antibodies following rhGH treatment of GHD from GH-gene deletion. Clinical trial studies have established the long-term efficacy and safety of rhIGF-I treatment in these patients (7). A recent publication showed that rhIGF-I stimulates linear growth in children with severe IGFD due to GH insensitivity whether or not there was an evidence of GHR abnormalities (8). Based on these studies, rhIGF-I was approved by the US Food and Drug Administration as therapy for severe primary IGFD defined by a height SDS $<-3$ and a basal IGF1 SDS $<-3$ and normal or elevated GH levels. More recently, rhIGF-I therapy was approved by the European Medicines Agency (EMEA) in children with primary IGFD defined by height SDS $<-3$ and a basal IGF1 percentile $<2.5$ (equivalent of -2 SDS) and normal or elevated GH. In these two indications, severe primary 
IGFD included patients with mutations in the GHR, defects in post-GHR signaling pathway, and IGF1 gene mutations. Moreover, secondary forms of IGFD are excluded, such as malnutrition, hypothyroidism or chronic treatment with pharmacologic doses of antiinflammatory steroids.

To date, the prevalence data of IGFD has been not evaluated thoroughly in Europe. The aims of this retrospective study were to assess the prevalence of primary IGFD in children with isolated SS, to describe this population, to discuss pathophysiology, and treatment.

\section{Subjects and methods}

\section{Subjects}

The study group comprised all short children admitted to our Endocrinology Unit in 2005, 2006, and 2007. Children were included according to the following criteria: i) SS with current height SDS below or equal to -2.5 , ii) age between 2 and 13 years in girls and 14 years in boys, and iii) prepubertal status, defined as Tanner-breast stage I for girls and testicular volume $<4 \mathrm{ml}$ for boys. Exclusion criteria were: i) identified cause of SS (identified syndromes or chromosomal defects, skeletal dysplasia, severe neurological impairment, severe chronic illness, chronic corticosteroid treatment), and ii) patients presently on rhGH therapy or having received either therapy. None of our patients had received rhIGF-I during this period.

\section{Methods}

For each child, the family history and parental heights were recorded, with calculation of the target height as absolute value and SDS. Birth weight and height were expressed as SDS with reference to gestational age according to the Usher \& McLean tables (9). SGA was defined as birth height and/or birth weight $\leq-2$ SDS according to the Usher \& McLean tables. Weight, height, and head circumference were expressed as absolute values and SDS, with reference to chronological age according to the French standards (10). Body mass index (BMI) was calculated as the ratio of weight in kilograms divided by the square of height in meters. BMI was expressed as Z-score (Zs) with reference to chronological age according to the French curves (11). Pubertal stage was assessed by Tanner's score (12). The onset of puberty was defined clinically by the appearance of breast development in girls and a testicular length of $30 \mathrm{~mm}$ or more in boys. Bone age was assessed using the atlas of Greulich \& Pyle (13).

\section{Assays}

Two assay kits were used to measure serum GH concentrations; one immunoradiometric (hGH, RIACT, CisBio, Gif sur Yvette, France) and the Nichols Automate Advantage (Nichols Institut Diagnostic, San Clemente, CA, USA). Both the assay standards and controls have been calibrated against the same international standard, the second World Health Organization International Reference Reagent for GH WHO second IS 98/574. IGF1 analysis was performed by means of IRMA kits either from DSL (Webster, TX, USA) or from Nichols (Nichols Institut Diagnostic), depending on the date of the test. All standards and controls have been calibrated against the WHO International Reference Reagent for IGF1 code $87 / 518$. The coefficient of variation (CV) of the methods was $<8 \%$ for the DSL and the Nichols tests. In order to define SDS for IFG1, we have established the reference values from 100 normal children aged 2-18 years with the DSL kit. We further established accurate correlation values between the values given by DSL and Nichols kits $\left(\right.$ Nichols $=0.882 \times$ DSL $\left.-19.84, R^{2}=0.8819\right)$. We used this correlation in order to define the SDS values in patients tested further with the Nichols kit. IGFD children were defined as children without GHD, which was defined as at least one GH peak above $7 \mu \mathrm{g} / \mathrm{l}$ under stimulation test, and with IGF1 levels below or equal to -2 SDS. GHD was defined as two GH peaks $<7 \mu \mathrm{g} / \mathrm{l}$ under stimulation test.

Serum IGF binding protein-3 (IGFBP-3) levels were measured by an IRMA kit from Immunotech (Marseille, France), with inter-assay CV being 9.5\%. IGF generation test involved daily s.c. injections of rhGH $(0.033 \mathrm{mg} / \mathrm{kg})$ at bedtime for five consecutive days as standardized by Blum et al. (14). Fasting blood samples were drawn in the morning before the first injection and on day 6 for IGF 1 and IGFBP-3 measurement.

The GH binding protein (GHBP) assay was performed with an ELISA kit from DSL with inter-assay CV being $8.3 \%$.

\section{Analysis of coding exons of the GHR}

Genomic DNA of the patient and a healthy control were extracted from peripheral blood leukocytes. The coding region of the GHR gene was PCR amplified from exon 2-10 in 12 fragments. The nucleotide sequences of the primers and conditions of PCR amplification are available on request. All coding exons were purified from an agarose gel with the QIAquick PCR purification kit (Qiagen $\mathrm{GmbH}$ ) and then directly sequenced by the dideoxy method using the DNA sequencing kit Big Dye Terminator Cycle Sequencing (PE Applied Biosystem, Foster City, CA, USA), at conditions recommended by the manufacturer. Sequencing reaction products were analyzed using the Applied Biosystem Model 3100 sequencer (PE Applied Biosystem). 


\section{Statistical methods}

The results are expressed as median values and ranges. For continuous variables, groups were compared using the non-parametric Mann-Whitney $U$-test. The $\chi^{2}$-test was used to compare percentages. Correlations were analyzed with Spearman's test. A value of $P<0.05$ was considered statistically significant.

\section{Results}

\section{Screening and frequency of IGFD}

We aimed to make precise the diagnostic process of patients with IGFD among patients referred for SS (height $\leq-2$ SDS). Children older than 2 years and prepubertal, with present height SDS below or equal to -2.5 and without identified cause of SS, were included. Patients screening process is shown in Fig. 1. Our final cohort comprised 65 prepubertal children with isolated SS below or equal to -2.5 SDS, all older than 2 years. In this cohort, $19(29 \%)$ children presented with GHD and $46(71 \%)$ children presented with non-GH-deficient SS, 22 born appropriate for gestational age (AGA), and

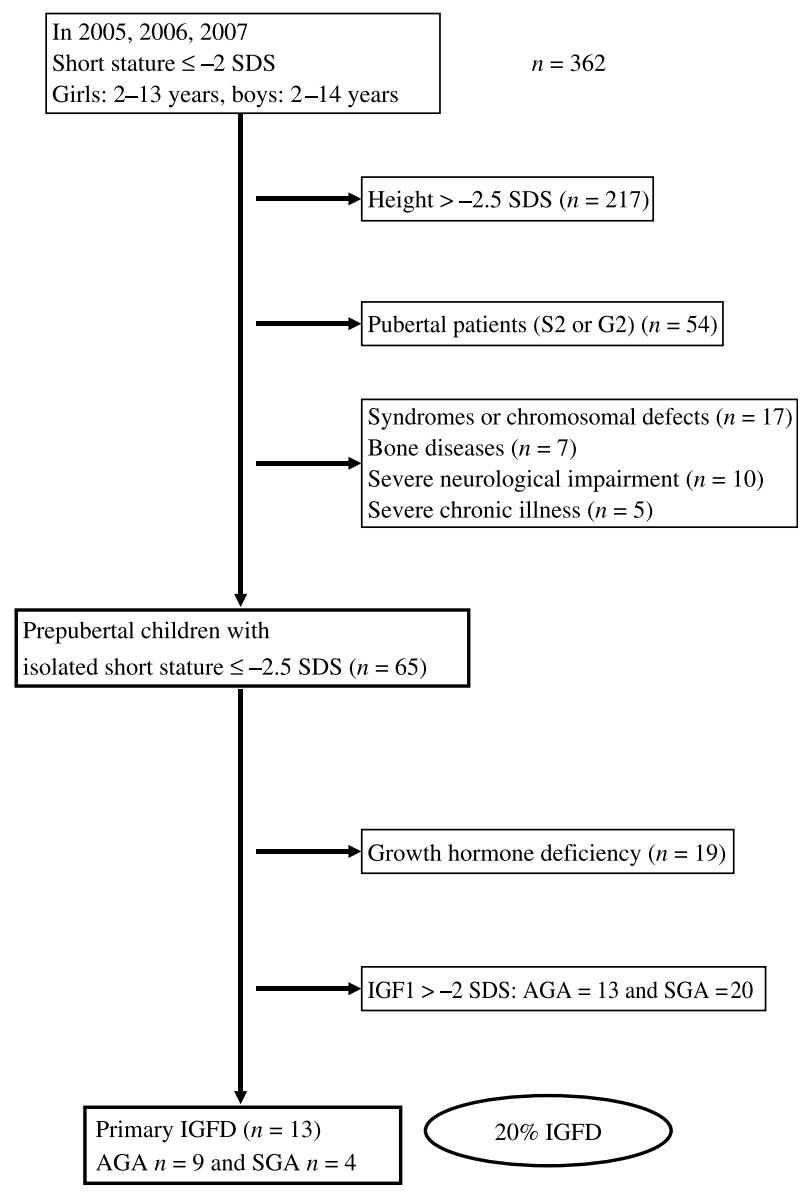

Figure 1 Screening process of patients with primary IGFD.

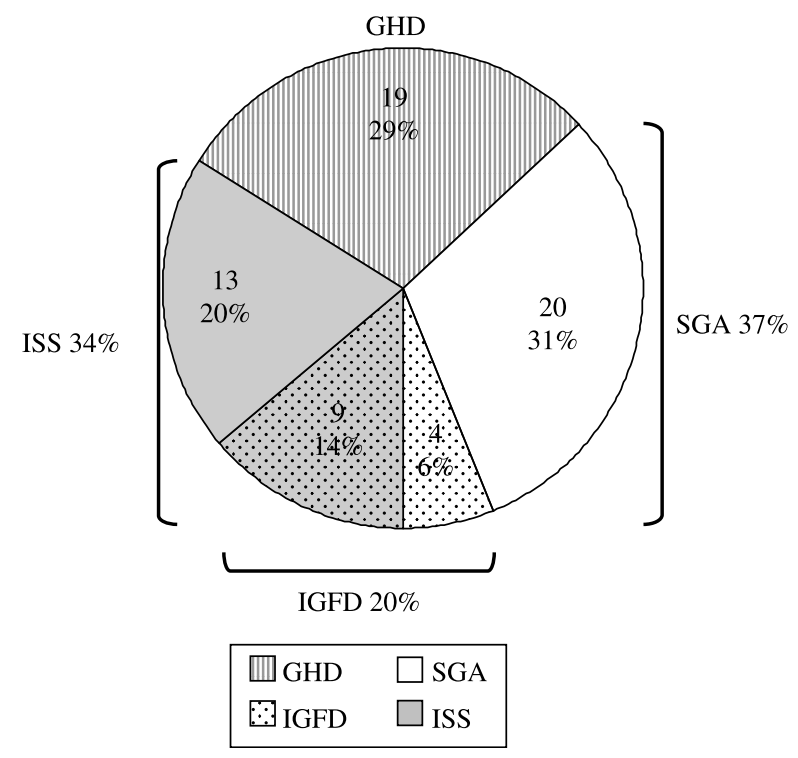

Figure 2 Frequency of primary IGFD in children with isolated short stature.

24 born SGA. Among the non-GH-deficient, 13 children, nine born AGA and four born SGA, had low IGF1 levels, consistent with a diagnosis of IGFD (Fig. 2). The prevalence of IGFD represents $20 \%$ of the entire original cohort of short children comprising 65 children.

The number of patients undergoing a GH stimulation test (normal peak GH $>7 \mu \mathrm{g} / \mathrm{l}$ ) and an IGF1 measurement (normal $>-2$ SDS) falling into each diagnostic category is shown in Table 1 .

\section{Auxological and hormonal characteristics of the 13 children with IGFD}

Auxological and hormonal characteristics, expressed as median value and ranges, of IGFD patients are shown in Table 2 and are compared with characteristics of nonIGFD and GHD patients.

All children with IGFD except one had a BMI above -2 Zs. Among IGFD children, when children born AGA were compared with children born SGA, the only significant difference, besides birth weight and height, was BMI (respectively, -0.6 vs $1.2 \mathrm{Zs}, P=0.03$ ). Three IGFD children (23\%) had a height below -3 SDS. When IGFD children were separated according to height (i.e. height between $>-3$ SDS and $\leq-2.5$, and height $\leq-3$ SDS), no difference in the auxological or hormonal data was found between these two groups. IGF1 levels were correlated with bone age $(P=0.03$, $\left.r^{2}=0.44\right)$, there was no correlation between IGF1 levels and the other data particularly BMI and GH peak.

When compared with non-IGFD children, IGFD children had higher birth weight $(-0.7$ vs -1 SDS, $P=0.02)$ and birth height $(-1.7$ vs -2 SDS, $P=0.04)$ and more delayed bone age (2.6 vs 1.7 years, $P=0.03)$. 
Table 1 Classification and frequency of GH-insulin-like growth factor 1 (IGF1) axis abnormalities.

\begin{tabular}{llllll}
\hline Peak GH level $(\mu \mathrm{g} / \mathrm{l})$ & IGF1 status $(\mathrm{SDS})$ & Patients $\%(n)$ & AGA \% $(n)$ & SGA \% $(n)$ & Diagnosis \\
\hline Normal, $>7$ & Normal, $>-2$ & $51(33)$ & $20(13)$ & $31(20)$ & Normal GH-IGF1 axis \\
Normal, $>7$ & Low, $\leq-2$ & $20(13)$ & $14(9)$ & $6(4)$ & IGFD \\
Low, $\leq 7$ & Normal, $>-2$ & $15(10)$ & & $8(5)$ & GHD \\
Low, $\leq 7$ & Low, $\leq-2$ & $14(9)$ & & $1.5(1)$ &
\end{tabular}

AGA, appropriate for gestational age; SGA, small for gestational age; SDS, SDS; GHD, GH deficiency; IGFD, IGF1 deficiency.

Between these two groups, there were no differences concerning the parental, auxological or hormonal data.

When compared with GHD children, IGFD children had higher target height $(-1$ vs -2 SDS, $P=0.003)$ and height $(-2.8$ vs -3.3 SDS, $P=0.05)$.

Precise auxological and hormonal characteristics and complementary analysis performed in IGFD children are shown in Table 3. IGFBB-3 levels were low in all but one patient. CV of IGF1 and IGFBP-3 expressed in percentage of baseline levels were obtained in four patients and abnormal in one. GHBP had been measured in only six patients and tended to be in the low-range values. Molecular studies of GHR were undertaken in three patients (patients' number 2, 6, and 8) and were normal in all cases.

When non-IGFD children were compared with GHD children, the only significant differences were target height (respectively -1.1 vs -2 SDS, $P=0.0023$ ), GH peak (respectively 10.5 vs $4.5 \mu \mathrm{g} / \mathrm{l}, P<0.0001$ ), and IGF1 levels (respectively -1.4 vs -1.7 SDS, $P=0.0002$ ).

\section{Discussion}

The aim of this retrospective study was to evaluate the prevalence of IGFD in prepubertal children with isolated SS below or equal to -2.5 SDS. IGF1-deficient children were defined as children without GHD, i.e. having had at least one $\mathrm{GH}$ peak above $7 \mu \mathrm{g} / \mathrm{l}$ under stimulation test, and with IGF1 levels below or equal to -2 SDS. In our entire cohort including 65 children, $20 \%$ of the children presented with IGFD, 14\% were born AGA and $6 \%$ were born SGA. In the Genentech National Cooperative Growth Study, IGFD represents 25\% of a cohort of 4663 short children (15), which is similar to that of Clayton's study in 190 short children (16). In these two studies, SS was defined by height below or equal to -2 SDS and IGFD by IGF1 levels below or equal to -2 SDS.

Children with SGA were not excluded from our study because persistent SS after SGA is a condition that may overlap from what is called ISS in that some etiologies

Table 2 Auxological and hormonal characteristics of IGF1 deficiency (IGFD) compared to non-IGFD and GH deficiency (GHD) children.

\begin{tabular}{|c|c|c|c|c|c|}
\hline & $\begin{array}{l}\text { Non-IGFD } \\
(n=33)\end{array}$ & $\begin{array}{c}P \text {-value IGFD } \\
\text { versus non-IGFD }\end{array}$ & $\begin{array}{l}\text { IGFD } \\
(n=13)\end{array}$ & $\begin{array}{l}P \text {-value IGFD } \\
\text { versus GHD }\end{array}$ & $\begin{array}{l}\text { GHD } \\
(n=19)\end{array}$ \\
\hline Sex (boys/girls) & $18 / 15$ & & $8 / 5$ & & $11 / 8$ \\
\hline Father height (SDS) & $-0.7(-2.4,1.7)$ & 0.420 & $-0.8(-1.9,0.3)$ & 0.095 & $-0.4(-1.9,0.6)$ \\
\hline $\begin{array}{l}\text { Father height } \leq-2 \\
\text { SDS (\%) }\end{array}$ & 9 & 0.618 & 0 & & 0 \\
\hline Mother height (SDS) & $-1.5(-3.1,1.2)$ & 0.588 & $-1.6(-3.1,0.3)$ & 0.686 & $-1.4(-2.9,1.4)$ \\
\hline $\begin{array}{l}\text { Mother height } \leq-2 \\
\text { SDS (\%) }\end{array}$ & 25 & 0.863 & 33 & 0.800 & 22 \\
\hline Target height (SDS) & $-1.1(-3.2,1)$ & 0.958 & $-1.1(-1.9,-0.7)$ & $0.003^{\dagger}$ & $-2(-3.8,0.3)$ \\
\hline $\begin{array}{l}\text { Target height }<-2 \\
\text { SDS (\%) }\end{array}$ & 19 & 0.2623 & 0 & 0.083 & 53 \\
\hline $\begin{array}{l}\text { Height-target } \\
\text { height (SDS) }\end{array}$ & $-1.6(-5,0.8)$ & 0.916 & $-1.7(-2.1,-1)$ & 0.565 & $-1.3(-4.9,1.3)$ \\
\hline $\begin{array}{l}\text { Height-target height } \\
<-2 \text { SDS (\%) }\end{array}$ & 37 & 0.100 & 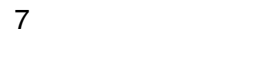 & 0.1013 & 41 \\
\hline Birth weight (SDS) & $-1(-3.6,1.9)$ & $0.012^{*}$ & $-0.7(-1.5,0.8)$ & 0.377 & $-0.8(-3.4,0.5)$ \\
\hline Birth height (SDS) & $-2(-6.2,0.2)$ & $0.040^{\star}$ & $-1.7(-3.1,0)$ & 0.659 & $-1.4(-4.7,-0.4)$ \\
\hline $\begin{array}{l}\text { Birth head circumference } \\
\text { (SDS) }\end{array}$ & $-0.6(-3.4,2)$ & 0.086 & $-0.1(-1,1.8)$ & 0.052 & $-1(-2.7,3.1)$ \\
\hline Chronological age (years) & $7.1(2,14.3)$ & 0.121 & $11(3.7,14)$ & 0.095 & $7.3(2.1,12.3)$ \\
\hline Height (SDS) & $-2.7(-5.1,-2.5)$ & 0.613 & $-2.6(-3.4,-2.5)$ & 0.055 & $-2.9(-6,-2.4)$ \\
\hline Weight (SDS) & $-2.2(-3.7,-1.2)$ & 0.633 & $-2.1(-3.1,-0.9)$ & 0.282 & $-2.5(-4.4,-1)$ \\
\hline BMI (Z-score) & $-0.3(-3.4,3)$ & 0.583 & $0.6(-2.7,1.6)$ & 0.161 & $-0.9(-3.9,1.2)$ \\
\hline Bone age delay (years) & $1.7(-0.5,4.5)$ & $0.030^{\star}$ & $2.6(1,3.7)$ & 0.260 & $2.1(0.2,7.3)$ \\
\hline $\mathrm{GH}$ peak $(\mu \mathrm{g} / \mathrm{l})$ & $10.5(7.4,24.3)$ & 0.583 & $11.8(7.1,25.2)$ & $<0.0001^{\ddagger}$ & $4.5(0.6,6.9)$ \\
\hline IGF1 (SDS) & $-1.4(-1.7,0.4)$ & $<0.0001^{\ddagger}$ & $-2(-2.5,-2)$ & $0.013^{\star}$ & $-1.7(-2.4,-0.8)$ \\
\hline
\end{tabular}

All data are expressed as median values and ranges unless indicated otherwise. For continuous variables, groups were compared using the non-parametric Mann-Whitney $U$-test. The $\chi^{2}$ test was used to compare percentages. ${ }^{\star} P<0.05,{ }^{\dagger} P<0.01,{ }^{\ddagger} P<0.001$. GH, GH; GHD, GH deficiency; IGF1, Insulin-like growth factor-I; IGFD, IGF1 deficiency; BMI, body mass index. 
Table 3 Auxological, hormonal characteristics, and complementary studies of the 13 children with primary insulin-like growth factor-I deficiency (IFGD).

\begin{tabular}{|c|c|c|c|c|c|c|c|c|c|c|c|c|c|c|}
\hline \multirow[b]{2}{*}{ No. } & \multirow[b]{2}{*}{ Sex } & \multirow{2}{*}{$\begin{array}{l}\text { BW } \\
\text { (SDS) }\end{array}$} & \multirow{2}{*}{$\begin{array}{c}\text { BH } \\
\text { (SDS) }\end{array}$} & \multirow{2}{*}{$\begin{array}{c}\text { Age } \\
\text { (year) }\end{array}$} & \multirow{2}{*}{$\begin{array}{c}\text { Height } \\
\text { (SDS) }\end{array}$} & \multirow{2}{*}{$\begin{array}{c}\text { GV } \\
\text { (SDS) }\end{array}$} & \multirow{2}{*}{$\begin{array}{l}\text { BMI } \\
(Z s)\end{array}$} & \multirow{2}{*}{$\begin{array}{c}\text { BA } \\
\text { delay } \\
\text { (year) }\end{array}$} & \multirow{2}{*}{$\begin{array}{c}\text { GH } \\
\text { peak } \\
(\mu \mathrm{g} / \mathrm{l})\end{array}$} & \multirow{2}{*}{$\begin{array}{l}\text { IGF1 } \\
\text { (SDS) }\end{array}$} & \multirow{2}{*}{$\begin{array}{c}\text { IGF } \\
\text { BP-3 } \\
\text { (SDS) }\end{array}$} & \multirow{2}{*}{$\begin{array}{c}\text { GHBP } \\
(\mathrm{pmol} / \mathrm{l})\end{array}$} & \multicolumn{2}{|c|}{ IGF generation test ${ }^{a}$} \\
\hline & & & & & & & & & & & & & IGF1 (\%) & IGF BP-3 (\%) \\
\hline 1 & M & -0.1 & -0.9 & 11.7 & -2.5 & -0.9 & 0.9 & 3.7 & 12.5 & -2.2 & -2.4 & & & \\
\hline 2 & $\mathrm{~F}$ & -0.3 & -1.1 & 7.5 & -2.5 & -0.9 & -1.9 & 1.8 & 7.7 & -2.1 & -2.8 & 135 & 57 & 22 \\
\hline 3 & $\mathrm{~F}$ & 0.0 & 0.0 & 12.6 & -2.6 & -1.0 & 1.2 & 2.6 & 25.2 & -2.0 & -3.0 & & & \\
\hline 4 & M & -0.1 & -0.6 & 11.6 & -2.6 & -1.2 & 1.2 & 2.6 & 10.5 & -2.1 & -2.4 & & & \\
\hline 5 & M & 0.7 & -1.7 & 3.7 & -2.7 & -2.1 & -1.6 & 1.0 & 11.0 & -2.0 & -2.2 & & & \\
\hline 6 & M & 0.8 & -0.3 & 4.3 & -2.8 & -1.8 & -2.7 & 2.3 & 7.1 & -2.0 & -2.3 & 140 & 7 & 0 \\
\hline 7 & $\mathrm{M}$ & -1.5 & -1.8 & 11.6 & -3.1 & -1.6 & 0.6 & 3.6 & 11.2 & -2.3 & -0.6 & & & \\
\hline 8 & $\mathrm{M}$ & -0.9 & -0.1 & 7.7 & -3.2 & -2.1 & -1.6 & 3.5 & 10.9 & -2.5 & -2.9 & 210 & 62 & 12 \\
\hline 9 & $M$ & -0.6 & -1.8 & 3.7 & -3.4 & -3.0 & -1.7 & 2.0 & 14.0 & -2.0 & -2.2 & 252 & & \\
\hline 10 & $\mathrm{~F}$ & -1.0 & -2.0 & 12.0 & -2.5 & -0.4 & 1.4 & 2.0 & 12.5 & -2.0 & -3.0 & & & \\
\hline 11 & $\mathrm{~F}$ & -0.8 & -2.2 & 6.4 & -2.6 & -2.4 & 1.5 & 2.4 & 7.4 & -2.0 & -2.7 & 264 & & \\
\hline 12 & $\mathrm{M}$ & -1.1 & -3.1 & 14.0 & -2.6 & -1.3 & 1.6 & 3.0 & 13.5 & -2.2 & -2.6 & & & \\
\hline 13 & $\mathrm{~F}$ & -1.0 & -2.0 & 11.0 & -2.9 & -2.4 & 0.5 & 2.0 & 16.1 & -2.2 & -2.9 & 510 & 51 & 54 \\
\hline
\end{tabular}

M, male; F, female; AGA, appropriate for gestational age; SGA, small for gestational age; IGF1, insulin-like growth factor 1; IGFD, IGF1 deficiency; BMI, body mass index; GV, growth velocity; BA, bone age.

${ }^{a}$ IGF generation test involved daily injection of rhGH $(0.033 \mathrm{mg} / \mathrm{kg})$ for 5 consecutive days, IGF1 and IGFBP-3 levels were measured before the first injection and on day 6 . Results were expressed as the coefficient of variation of IGF1 and IGFBP-3 expressed in percentage of baseline levels.

might cause both the two conditions. Moreover, the distinction between idiopathic SGA and ISS may be arbitrary in that the Gaussian distribution of birth weight and birth length in ISS is shifted to the left by 1 SDS. So children with a birth weight or length below -2 SDS can be considered as the left tail of the distribution for children with ISS (17).

In our entire cohort, $71 \%$ of the children presented with isolated non-GH-deficient SS, of which $52 \%$ were born SGA. Of the children referred to specialized growth centers because of SS, the percentage with no organic causes for their impaired growth was about $70 \%$, with $76 \%$ ( 212 out of 278 children) and $60 \%$ (119 out of 198 ) in the studies of Grimberg et al. and Green et al. respectively $(18,19)$. In these reports, the percentage of short children born SGA was not clear. In our study, $40 \%$ (9 out of 22) of the ISS children and 16\% (4 out of 24) of the children born SGA presented IGFD.

In our study, it was unexpected that children with IGFD presented with higher birth weight $(-0.7$ vs -1 SDS, $P=0.02)$ and birth height $(-1.7$ vs -2 SDS, $P=0.04)$ than children without IGFD. Indeed, IGF1 plays a major role in the prenatal growth and patients with deletion in the IGF1 gene or mutations in the IGF1 receptor presented with marked SGA $(20,21)$. These unexpected results may be partly explained by the greater number of SGA patients among non-IGFD patients compared to IGFD patients (60 vs 30\%) in our study. Moreover, it should be noted that children with IGFD presented with lower birth weight and height compared to the normal population.

IGF1 is regulated by GH, but also by nutritional intake and by age. Therefore, IGFD could be secondary not only to GHD but also to nutritional deficiency or to maturational delay.

There is evidence that nutritional deficiency contributes to ISS (22) and is also associated with lower IGF1 levels. In our study, children with IGFD presented normal BMI, however, BMI is significantly lower in ISS children compared with children born SGA (respectively, -0.6 vs $1.2 \mathrm{Zs}, P=0.03$ ). When ISS subpopulation was studied, despite no statistical difference, the BMI was lower for the IGFD children compared with non-IGFD children (respectively, -0.6 vs $0.3 \mathrm{Zs}$ ); this finding could reflect that some of the IGFD may be partly explained by nutritional deficiency. In the ISS population, no significant correlation between BMI and IGF1 was found as suggested by some previous studies (23).

Many children with SS have some degree of maturational delay, including delayed bone age, dental age, and puberty $(24,25)$; this condition is often called constitutional delay in growth and maturation. Because serum IGF1 levels are correlated with skeletal maturation $(26,27)$ and increase with age, even before puberty, a maturational delay might include a delayed rise in IGF1. In our study, when compared with nonIGFD children, IGFD children had significantly more delayed bone age (2.7 vs 1.7 years, $P=0.03)$, in addition IGF1 levels were correlated with bone age $\left(P=0.03, r^{2}=0.44\right)$. These data confirm the relationship between maturational delay and IGFD.

Finally, IGFD could be secondary to GH insensitivity (GHI). As impaired IGF production leads to an increase in GH secretion, decreased IGF1 is associated with elevated GH in complete GHI.

As previously reported, the children with ISS tended to have serum IGF1 concentrations in the lower portion of the normal range or below the lower limits of normal. Moreover, these subjects also failed to raise their serum IGF1 concentrations in response to GH (28). Several studies suggested that a subset of children with ISS has some degree of GHI $(29,30)$. Concerning neonates born SGA, they show increased levels of GH and reduced 
IGF1 and IGFBP-3 concentrations, suggesting that these newborns present GH insensitivity (31-33). This alteration in the GH-IGF axis is transient, however, and normalization of GH, IGF1, and IGFBP-3 secretion occurs in early postnatal life (34). In short children born SGA, hormonal status is variable. Some of them show normal GH responses to stimulation testing and normal serum levels of IGF1 and IGFBP-3 (35). However, several studies have reported altered patterns of spontaneous $\mathrm{GH}$ release associated with a reduced concentration of IGF1, suggesting GH insufficiency (3638). A case-control study of older children who were born SGA did not show any significant differences in IGF1 and IGFBP-3 levels between short and normal SGA (39), and no relationship was found between the IGFrelated variables at birth and during postnatal growth (31). The large variation in hormone sensitivity patterns in patients with SGA explains the inability to classify SGA patients according to the relative $\mathrm{GH}$ and IGF1 concentrations (40).

Children with IGFD should be further analyzed in terms of GHI syndrome. In our IGFD patients, low serum levels of IGF1 were associated with low serum levels of IGFBP-3 suggestive of GHI. In patients with IGFD, the IGF1 generation test could be helpful in differentiating between low serum levels of IGF1 that are responsive, or partially responsive to rhGH, from low serum levels of IGF1 that do not respond to rhGH administration with an increase in IGF1 levels and would not be expected to respond to rhGH treatment with an improvement in linear growth and adult height. However, because of controversies regarding the optimal protocol, diagnostic interpretation, lack of assay standardization, and nearly no correlation of test results with the clinical response to rh $\mathrm{GH}$, there is a need for more studies in this area (41). In our study, four IGF1 generation tests were performed and only one (patient 6) showed no increment in IGF1 and IGFBP-3 levels; in this child, the molecular study of the GHR was normal. The GHBP levels performed in six children were low in all cases. Serum GHBP level generally correlates positively with GHR and GH activity. In addition to complete GHI secondary to mutation in the GHR gene, several clinical GH-resistant conditions, such as liver cirrhosis, renal insufficiency, insulin-dependent diabetes mellitus, hypothyroidism, malnutrition and critical illness, are associated with reduced GHBP levels (42).

Many studies have now demonstrated the efficacy of rhIGF-I in increasing growth in conditions of low serum IGF1 in which rhGH administration is not effective, including GHR mutations, post-receptor signal transduction defects, GH gene deletions with inhibitory GH antibodies after GH treatment and IGF1 gene deletion. These conditions are approved indications for rhIGF-I treatment. In our study, only three patients fulfilled the EMEA criteria for IGF1 treatment recommendations. These patients presented with height SDS below -3 and IGF1 SDS below -2, and secondary forms of IGFD were excluded, such as malnutrition, hypothyroidism or chronic treatment with pharmacologic doses of antiinflammatory steroids. However, no particular etiology was found in these patients. The role of rhIGF-I administration in ISS patients is presently unclear. Carefully controlled prospective studies are necessary to determine the benefits of rhIGF-I treatment compared with rhGH treatment. Moreover, considerations of economic, social or psychological costs are in addition to the therapeutic concerns of safety and efficacy and the risk to benefit ratio. Although presently, many growth disorders are still diagnosed and treated on empirical bases, it might soon be possible to stratify patients predominantly by genetic defect, with treatment based on our molecular understanding of the role of the affected gene in the disease (43).

In conclusion, the prevalence of primary IGFD was $20 \%$ in the children of our study with isolated SS. Concerning the pathophysiology, our study emphasize that IGFD in some children may be secondary to nutritional deficiency or to maturational delay.

\section{Declaration of interest}

There is no conflict of interest that could be perceived as prejudicing the impartiality of the research reported.

\section{Funding}

This work was supported by BEAUFOUR IPSEN PHARMA France.

\section{Acknowledgements}

We thank Dr Mireille Bonnemaire for reviewing the manuscript.

\section{References}

1 Maghnie M, Ambrosini L, Cappa M, Pozzobon G, Ghizzoni L, Ubertini MG, di Iorgi N, Tinelli C, Pilia S, Chiumello G, Lorini R \& Loche S. Adult height in patients with permanent growth hormone deficiency with and without multiple pituitary hormone deficiencies. Journal of Clinical Endocrinology and Metabolism 2006 $912900-2905$.

2 Soriano-Guillen L, Coste J, Ecosse E, Leger J, Tauber M, Cabrol S, Nicolino M, Brauner R, Chaussain JL \& Carel JC. Adult height and pubertal growth in Turner syndrome after treatment with recombinant growth hormone. Journal of Clinical Endocrinology and Metabolism 200590 5197-5204.

3 Van Pareren Y, Mulder P, Houdijk M, Jansen M, Reeser M \& Hokken-Koelega A. Adult height after long-term, continuous growth hormone $(\mathrm{GH})$ treatment in short children born small for gestational age: results of a randomized, double-blind, doseresponse GH trial. Journal of Clinical Endocrinology and Metabolism 200388 3584-3590.

4 Wit JM, Rekers-Mombarg LT, Cutler GB, Crowe B, Beck TJ, Roberts K, Gill A, Chaussain JL, Frisch H, Yturriaga R \& Attanasio AF. Growth hormone (GH) treatment to final height in children with idiopathic short stature: evidence for a dose effect. Journal of Pediatrics 2005146 45-53. 
5 Wit JM, Kamp GA \& Rikken B. Spontaneous growth and response to growth hormone treatment in children with growth hormone deficiency and idiopathic short stature. Pediatric Research 199639 295-302.

6 Ranke MB. Defining insulin-like growth factor-I deficiency. Hormone Research 200665 9-14.

7 Laron Z. Laron syndrome (primary growth hormone resistance or insensitivity): the personal experience 1958-2003. Journal of Clinical Endocrinology and Metabolism 200489 1031-1044.

8 Chernausek SD, Backeljauw PF, Frane J, Kuntze J \& Underwood LE. Long-term treatment with recombinant insulin-like growth factor (IGF)-I in children with severe IGF-1 deficiency due to growth hormone insensitivity. Journal of Clinical Endocrinology and Metabolism 200792 902-910.

9 Usher R \& McLean F. Intrauterine growth of live-born Caucasian infants at sea level: standards obtained from measurements in 7 dimensions of infants born between 25 and 44 weeks of gestation. Journal of Pediatrics 196974 901-910.

10 Sempe MPG \& Roy-Pernot MP. Auxologie, Méthodes et Séquences. Paris: Laboratoire Théraplix, 1979.

11 Rolland-Cachera MF, Cole TJ, Sempe M, Tichet J, Rossignol C \& Charraud A. Body mass index variations: centiles from birth to 87 years. European Journal of Clinical Nutrition 199145 13-21.

12 Tanner J. Growth and Adolescence. Oxford: Blackwell, 1969.

13 Greulich W. Radiographic Atlas of Skeletal Development of the Hand and Wrist. Stanford: University Press, 1959.

14 Blum WF, Cotterill AM, Postel-Vinay MC, Ranke MB, Savage MO \& Wilton P. Improvement of diagnostic criteria in growth hormone insensitivity syndrome: solutions and pitfalls. Pharmacia study group on insulin-like growth factor I treatment in growth hormone insensitivity syndromes. Acta Paediatrica 1994399 117-124.

15 Attie KM, Julius JR, Stoppani C \& Rundle AC. National Cooperative Growth Study substudy VI: the clinical utility of growth-hormonebinding protein, insulin-like growth factor I, and insulin-like growth factor-binding protein 3 measurements. Journal of Pediatrics 1997131 S56-S60.

16 Clayton PE, Ayoola O \& Whatmore AJ. Patient selection for IGF-1 therapy. Hormone Research 200665 28-34.

17 Wit JM, Finken MJ, Rijken M \& de Zegher F. Preterm growth restraint: a paradigm that unifies intrauterine growth retardation and preterm extrauterine growth retardation and has implications for the small-for-gestational-age indication in growth hormone therapy. Pediatrics 2006117 793-795.

18 Grimberg A, Kutikov JK \& Cucchiara AJ. Sex differences in patients referred for evaluation of poor growth. Journal of Pediatrics 2005 $146212-216$.

19 Green AA \& MacFarlane JA. Method for the earlier recognition of abnormal stature. Archives of Disease in Childhood $1983 \mathbf{5 8}$ 535-537.

20 Abuzzahab MJ, Schneider A, Goddard A, Grigorescu F, Lautier C, Keller E, Kiess W, Klammt J, Kratzsch J, Osgood D, Pfaffle R, Raile K, Seidel B, Smith RJ \& Chernausek SD. IGF-1 receptor mutations resulting in intrauterine and postnatal growth retardation. New England Journal of Medicine $20033492211-2222$.

21 Woods KA, Camacho-Hubner C, Savage MO \& Clark AJ Intrauterine growth retardation and postnatal growth failure associated with deletion of the insulin-like growth factor I gene. New England Journal of Medicine 1996335 1363-1367.

22 Wudy SA, Hagemann S, Dempfle A, Ringler G, Blum WF, Berthold LD, Alzen G, Gortner L \& Hebebrand J. Children with idiopathic short stature are poor eaters and have decreased body mass index. Pediatrics 2005116 52-57.

23 Oerter KE, Sobel AM, Rose SR, Cristiano A, Malley JD, Cutler GB Jr \& Baron J. Combining insulin-like growth factor-I and mean spontaneous nighttime growth hormone levels for the diagnosis of growth hormone deficiency. Journal of Clinical Endocrinology and Metabolism 199275 1413-1420.

24 Wit JM, Clayton PE, Rogol AD, Savage MO, Saenger PH \& Cohen P. Idiopathic short stature: definition, epidemiology, and diagnostic evaluation. Growth Hormone and IGF Research 200818 89-110.
25 Gaethofs M, Verdonck A, Carels C \& de Zegher F. Delayed dental age in boys with constitutionally delayed puberty. European Journal of Orthodontics 199921 711-715.

26 Reinehr T, de Sousa G \& Wabitsch M. Relationships of IGF-1 and androgens to skeletal maturation in obese children and adolescents. Journal of Pediatric Endocrinology and Metabolism 200619 1133-1140.

27 Leger J, Mercat I, Alberti C, Chevenne D, Armoogum P, Tichet J \& Czernichow P. The relationship between the GH/IGF-1 axis and serum markers of bone turnover metabolism in healthy children. European Journal of Endocrinology 2007157 685-692.

28 Cohen P, Rogol AD, Howard CP, Bright GM, Kappelgaard AM \& Rosenfeld RG. Insulin growth factor-based dosing of growth hormone therapy in children: a randomized, controlled study. Journal of Clinical Endocrinology and Metabolism $2007 \mathbf{9 2}$ 2480-2486.

29 Attie KM, Carlsson LM, Rundle AC \& Sherman BM. Evidence for partial growth hormone insensitivity among patients with idiopathic short stature. The National Cooperative Growth Study. Journal of Pediatrics 1995127 244-250.

30 Buckway CK, Guevara-Aguirre J, Pratt KL, Burren CP \& Rosenfeld RG. The IGF-1 generation test revisited: a marker of GH sensitivity. Journal of Clinical Endocrinology and Metabolism $2001865176-5183$.

31 Leger J, Noel M, Limal JM \& Czernichow P. Growth factors and intrauterine growth retardation. II. Serum growth hormone, insulin-like growth factor (IGF) I, and IGF-binding protein 3 levels in children with intrauterine growth retardation compared with normal control subjects: prospective study from birth to two years of age. Study Group of IUGR. Pediatric Research $1996 \mathbf{4 0} 101-107$.

32 Deiber M, Chatelain P, Naville D, Putet G \& Salle B. Functional hypersomatotropism in small for gestational age (SGA) newborn infants. Journal of Clinical Endocrinology and Metabolism 198968 232-234.

33 de Zegher F, Kimpen J, Raus J \& Vanderschueren-Lodeweyckx M. Hypersomatotropism in the dysmature infant at term and preterm birth. Biology of the Neonate $1990 \mathbf{5 8} 188-191$.

34 Cianfarani S, Germani D, Rossi P, Rossi L, Germani A, Ossicini C, Zuppa A, Argiro G, Holly JM \& Branca F. Intrauterine growth retardation: evidence for the activation of the insulin-like growth factor (IGF)-related growth-promoting machinery and the presence of a cation-independent IGF binding protein-3 proteolytic activity by two months of life. Pediatric Research 1998 44 374-380.

35 Grunt JA, Howard CP \& Daughaday WH. Comparison of growth and somatomedin $\mathrm{C}$ responses following growth hormone treatment in children with small-for-date short stature, significant idiopathic short stature and hypopituitarism. Acta Endocrinologica $1984106168-174$.

36 Ackland FM, Stanhope R, Eyre C, Hamill G, Jones J \& Preece MA. Physiological growth hormone secretion in children with short stature and intra-uterine growth retardation. Hormone Research $198830241-245$.

37 de Waal WJ, Hokken-Koelega AC, Stijnen T, de Muinck KeizerSchrama SM \& Drop SL. Endogenous and stimulated GH secretion, urinary GH excretion, and plasma IGF-1 and IGF-1I levels in prepubertal children with short stature after intrauterine growth retardation. The Dutch Working Group on Growth Hormone. Clinical Endocrinology 199441 621-630.

38 Boguszewski M, Rosberg S \& Albertsson-Wikland K. Spontaneous 24-hour growth hormone profiles in prepubertal small for gestational age children. Journal of Clinical Endocrinology and Metabolism $1995 \mathbf{8 0} 2599-2606$.

39 Cianfarani S, Maiorana A, Geremia C, Scire G, Spadoni GL \& Germani D. Blood glucose concentrations are reduced in children born small for gestational age (SGA), and thyroid-stimulating hormone levels are increased in SGA with blunted postnatal catchup growth. Journal of Clinical Endocrinology and Metabolism 2003 88 2699-2705. 
40 Ranke MB. Sensitivity to IGF-1 in short children born small for gestational age. Journal of Endocrinological Investigation 2006 29 21-26.

41 Collett-Solberg PF \& Misra M. The role of recombinant human insulin-like growth factor-I in treating children with short stature. Journal of Clinical Endocrinology and Metabolism 200893 10-18.

42 Amit T, Youdim MB \& Hochberg Z. Clinical review 112: does serum growth hormone $(\mathrm{GH})$ binding protein reflect human $\mathrm{GH}$ receptor function? Journal of Clinical Endocrinology and Metabolism 200085 927-932.
43 Pilecka I, Whatmore A, Hooft van Huijsduijnen R, Destenaves B \& Clayton P. Growth hormone signalling: sprouting links between pathways, human genetics and therapeutic options. Trends in Endocrinology and Metabolism $2007 \mathbf{1 8} 12-18$.

Received 30 March 2009

Accepted 28 April 2009 